\title{
HUBUNGAN TINGKAT PENGETAHUAN TENTANG PENGENDALIAN HIPERTENSI DAN TINGKAT PEMANFAATAN FASILITAS KESEHATAN DENGAN TERJADINYA HIPERTENSI DI WILAYAH KERJA PUSKESMAS SUNGAI KAKAP
}

\author{
Wandira $^{1}$, Uti Rusdian Hidayat ${ }^{2}$, Aryanto Purnomo ${ }^{3}$ \\ 1.2 STIKes Yarsi Pontianak 3. Poltekkes Kemenkes Pontianak \\ Wandira : Program Studi Pendidikan Profesi Ners, STIKes Yarsi Pontianak, \\ Jln. Panglima A’im, No.1 Pontianak Timur, Kalimantan Barat -78232 \\ E-mail:wandira032@gmail.com
}

\begin{abstract}
ABSTRAK
Latar Belakang: Hipertensi disebut sebagai silent killer karena sebagian besar kasus hipertensi dimasyarakat akibat dari penderita tidak menyadari bahwa dia menderita hipertensi karena tidak mendapat gejala, pengontrolan yang kurang dan tidak rutin serta tidak minum obat sesuai anjuran petugas kesehatan.

Tujuan: untuk mengetahui hubungan tingkat pengetahuan tentang pengendalian hipertensi dan pemanfaatan fasilitas kesehatan dengan terjadinya hipertensi di wilayah kerja Puskesmas Sungai Kakap.

Metode: penelitian kuantitatif menggunakan rancangan penelitian observasional analitik korelatif dengan desain penelitian case control. Besar sampel yaitu 68 orang yang diambil dengan teknik purposive sampling. Analisa data menggunakan uji chi square, dengan nilai $\mathrm{P}<0,05$.

Hasil: hubungan tingkat pengetahuan tentang pengendalian hipertensi dengan terjadinya hipertensi $(\mathrm{p}$ value $=0,000)$ dan pemanfaatan fasilitas kesehatan dengan dengan terjadinya hipertensi ( $\mathrm{p}$ value $=0,002$ ).

Kesimpulan: Terdapat Hubungan yang signifikan tingkat pengetahuan tentang pengendalian hipertensi dan tingkat pemanfaatan fasilitas kesehatan dengan terjadinya hipertensi.

Kata Kunci: Hipertensi, Pengetahuan, Pemanfaatan fasilitas kesehatan.
\end{abstract}

\begin{abstract}
Background: Hypertension is called a silent killer because most cases of hypertension in the community as a result of sufferers do not realize that he is suffering from hypertension because he does not get symptoms. Poor and irregular control and not taking medication as recommended by health workers.

Purpose: to determine the relationship between the level of knowledge about hypertension control and the use of health facilities for the occurrence of hypertension in the working area of the Sungai Kakap community health center.

Method: quantitative research using a correlative analytic observational research design with case control research design. The sample size is 68 people taken by purposive sampling technique. Data analysis using chi square test, with a value of $p<0,05$.

Results: the relationship between the level of knowledge about controlling hypertension and the occurrence of hypertension ( $p$ value $=0,000)$ and the utilization of health facilities with the occurrence of hypertension $(p$ value $=$ 0,002).

Conclusion: there is a significant correlation between the level of knowledge about hypertension control and the level of utilization health facilities with the occurrence of hypertension.
\end{abstract}

Keyword: Hypertension, Knowledge, Utilization of health facilities.

\section{PENDAHULUAN}

Hipertensi disebut sebagai silent killer karena sebagian besar kasus hipertensi dimasyarakat akibat dari penderita tidak menyadari bahwa dia menderita hipertensi karena tidak mendapat gejala, pengontrolan yang kurang dan tidak rutin serta tidak minum obat sesuai anjuran petugas kesehatan. Beberapa dari alasan mereka diketahui sudah merasa sehat dan tidak rutin melakukan pemeriksaan ke fasilitas pelayanan kesehatan serta meminum obat tradisional (Riskesdas, 2018). Data WHO 2015, menunjukkan 1,13 miliar orang di dunia menderita hipertensi. Artinya 1 dari 3 orang di dunia terdiagnosis 
menderita hipertensi, hanya 36,8\% diantaranya minum obat. Jumlah penderita hipertensi di dunia terus meningkat setiap tahunnya, di perkirakan pada tahun 2025 akan ada 1,15 miliar orang yang terkena hipertensi dan ada 9,4 juta orang meninggal akibat hipertensi dan komplikasi (Kemenkes 2018). Riset Kesehatan Dasar (Riskesdas) 2018, di Indonesia memperoleh data prevalensi kejadian penyakit tidak menular mengalami kenaikan jika dibandingkan Riskesdas 2013, antara lain kanker, stroke, penyakit ginjal kronis, diabetes melitus, dan hipertensi. Hasil pengukuran tekanan darah penduduk usia $\geq$ 18 tahun penderita hipertensi naik dari 25,8\% menjadi $34,1 \%$ dengan 185.857 kasus. Dinas kesehatan melalui profil kesehatan provinsi Kalimantan Barat tahun 2017 menunjukkan bahwa hipertensi menduduki urutan ke tiga menjadi 23,5\% dengan 15.681 kasus dari sepuluh penyakit yang tertinggi di provinsi Kalimantan Barat.

Berdasarkan data tahun 2018 dari 15.815 kasus hipertensi tertinggi terjadi di kabupaten Kubu Raya terdapat 2.199 kasus hipertensi terbanyak berada pada daerah wilayah kerja Puskesmas Sungai Kakap. Menurut data kunjungan Puskesmas Kabupaten Kubu Raya mencapai 91.835 dan 5.966 orang berada di Puskesmas Sungai Kakap (Data Dinas Kabupaten Kubu Raya, 2018). Di Puskesmas Sungai Kakap penderita hipertensi yang telah diberikan surat keterangan pemberian obat yang dibawa pulang sekitar 10 hari kemudian melakukan kunjungan ulang sehingga angka kunjungan yang dianjurkan dalam 1 bulan bisa 3 kali kunjungan dengan total 36 kali kunjungan dalam setahun. Berdasarkan rata-rata jumlah penderita hipertensi dengan frekuensi kunjungan ke puskesmas yaitu hanya 2,71 kali dalam setahun untuk setiap penderita terbilang sangat rendah. Dari data kunjungan penderita hipertensi ke puskesmas dari bulan Januari sampai Maret sebanyak 68 orang. (Data Puskesmas Sungai Kakap, 2019).

Pengetahuan manajemen hipertensi yang rendah dapat menyebabkan tidak terkontrolnya tekanan darah dan timbulnya komplikasi penyakit lain (Ulya, dkk. (2017).
Menurut Wulansari, dkk (2013), ada hubungan yang signifikan antara pengetahuan tentang hipertensi dengan pengendalian tekanan darah pada pasien hipertensi di Poliklinik Penyakit Dalam RSUD dr. Moewardi Surakarta.

Sedangkan menurut Hesriantica \& Diana (2017), kesimpulan yang dapat ditarik adalah tidak ada hubungan antara tindakan pengendalian dan pengetahuan lansia. Hubungan yang terdapat antara riwayat hipertensi dengan tindakan pengendalian adalah hubungan yang rendah. Disarankan untuk adanya penyebaran informasi tentang hipertensi pada lansia di Posyandu melalui penyuluhan ataupun adanya media.

Dalam penelitian lain Putri, dkk. (2015), diperoleh simpulan 1. Tidak ada hubungan antara jenis kelamin, tingkat pendidikan formal, dan pendapatan keluarga dengan kepatuhan pengobatan pada penderita hipertensi. 2. Ada hubungan antara status pekerjaan, jarak rumah terhadap pelayanan kesehatan, tingkat pengetahuan tentang tatalaksana hipertensi, motivasi untuk berobat, dan dukungan keluarga dengan kepatuhan pengobatan pada penderita hipertensi.

Hasil studi pendahuluan dilakukan bulan maret 2019 dengan penderita hipertensi di wilayah kerja Puskesmas Sungai Kakap Kabupaten Kubu Raya. Pada 10 orang yang menderita hipertensi terdapat 2 orang paham tentang hipertensi dan penanganannya. Kemudian 5 orang menyatakan tidak banyak mengetahui penyebab hipertensi dan hanya melakukan pemeriksaan tekanan darah apabila sudah ada tanda dan gejala berat yang dialaminya. Selanjutnya 3 orang lainnya mengatakan tidak tahu apa itu hipertensi dan penanganannya serta pergi ke puskesmas jika tidak tahan lagi dengan sakitnya. Hal ini menunjukkan kurangnya pengetahuan dan kesalahan persepsi tentang konsep sehat-sakit khususnya fenomena yang berkaitan dengan hipertensi pada masyarakat di wilayah kerja Sungai Kakap. Berdasarkan penjelasan diatas, peneliti ingin mengetahui apakah tingkat pengetahuan tentang pengendalian hipertensi dan tingkat pemanfatan fasilitas kesehatan 
benar-benar berhubungan dengan terjadinya hipertensi.

\section{METODE}

Penelitian ini menggunakan jenis penelitian kuantitatif dengan rancangan observasional analitik korelatif. Penelitian ini menggunakan desain penelitian case control yang dilaksanakan di wilayah kerja Puskesmas Sungai Kakap Kecamatan Sungai Kakap Kabupaten Kubu Raya selama 1 bulan mulai dari pengumpulan data sampai analisis data. Populasi pada penelitian ini yaitu sebanyak 68 orang terhitung dari bulan Januari - Maret 2019. Pengambilan sampel menggunakan teknik Non Probability Sampling, jenis yang dipilih yaitu purposive sampling didapatkan sebanyak 34 orang kelompok intervensi dan 34 orang kelompok kontrol instrument penelitian menggunakan kuesioner sebanyak 16 item pertanyaan dan pernyataan yang telah diuji validitas dan reliabelitasnya. Sasaran responden yaitu penderita hipertensi dan bukan penderita hipertensi yang melakukan kunjungan ke Puskesmas Sungai Kakap. Peneliti terlebih dahulu meminta persetujuan responden melalui inform consent yang telah di tandatangani kemudian kuesioner dibagikan untuk diisi oleh responden, setelah itu diinput menggunakan program komputer dan diolah menggunakan software analisa statistik. Analisa data menggunakan uji Chi square.

\section{HASIL DAN PEMBAHASAN}

1. Hasil Analisa Univariat dan Pembahasan

Tabel 1

Distribusi frekuensi responden berdasarkan usia, jenis kelamin, pendidikan, pekerjaan di wilayah kerja Puskesmas Sungai Kakap

\begin{tabular}{lcc|cc}
\hline \multirow{2}{*}{ Karakteristik } & \multicolumn{2}{c|}{ Kasus } & \multicolumn{2}{c}{ Kontrol } \\
\cline { 2 - 5 } & $\mathrm{n}$ & $\%$ & $\mathrm{n}$ & $\%$ \\
\hline Jenis kelamin & & & & \\
Laki-laki & 14 & 41.2 & 12 & 35.3 \\
Perempuan & 20 & 58.8 & 22 & 64.7 \\
Total & 34 & 100.0 & 34 & 100.0 \\
\hline
\end{tabular}




\begin{tabular}{lrrrr} 
Usia & & & & \\
$18-40$ & 11 & 32.4 & 16 & 47.1 \\
$41-60$ & 18 & 52.9 & 15 & 44.1 \\
$>60$ & 5 & 14.7 & 3 & 8.8 \\
Total & 34 & 100.0 & 34 & 100.0 \\
\hline Pendidikan & & & & \\
Tidak Sekolah & 2 & 5.9 & 6 & 17.6 \\
SD & 17 & 50.0 & 15 & 44.1 \\
SMP & 4 & 11.8 & 3 & 8.8 \\
SMA & 9 & 26.5 & 8 & 23.5 \\
Perguruan & 2 & 5.9 & 2 & 5.9 \\
Tinggi & & & & \\
Total & 34 & 100.0 & 34 & 100.0 \\
\hline Pekerjaan & & & & \\
Pelajar/Mahas & & & 3 & 8.8 \\
iswa & & & & \\
PNS & 4 & 11.8 & 1 & 2.9 \\
Swasta/Nelay & 13 & 38.2 & 9 & 26.5 \\
an/Petani & & & & \\
Ibu Rumah & 17 & 50.0 & 21 & 61.8 \\
Tangga & & & & \\
Total & 34 & 100.0 & 34 & 100.0 \\
\hline Sumber:daprimer & 2019 & & &
\end{tabular}

Sumber:data primer 2019

Hasil penelitian menunjukkan jenis kelamin responden lebih banyak perempuan sebanyak 42 responden $(61,8 \%)$ diantaranya 20 responden berada pada kelompok kasus. Notoatmodjo, (2010) dalam hal menjaga kesehatan, biasanya kaum perempuan lebih memperhatikan kesehatannya dibandingkan dengan laki-laki. Perbedaan pola perilaku sakit juga dipengaruhi oleh jenis kelamin, perempuan lebih sering mengobatkan dirinya dibandingkan dengan laki-laki. Hal ini dapat dikaitkan dengan ketersediaan waktu dan kesempatan bagi perempuan untuk datang ke puskesmas lebih banyak dibandingkan dengan laki-laki. Namun, saat ini perempuan tidak selalu memiliki ketersedian waktu untuk datang ke puskesmas karena banyak perempuan yang juga ikut bekerja/mempunyai kesibukan.

Hasil penelitian Novitaningtyas, $\mathrm{T}$. (2014) mengatakan tidak ada hubungan antara jenis kelamin dengan tekanan darah pada lansia. Rata-rata perempuan akan mengalami peningkatan resiko tekanan darah tinggi (hipertensi) setelah menopause yaitu diatas 45 tahun. Perempuan yang belum menopause dilindungi oleh hormon estrogen yang berperan dalam meningkatkan kadar High Density Lipoprotein (HDL). Kadar kolesterol HDL rendah dan tingginya kadar LDL (Low Density Lipoprotein) mempengaruhi terjadinya proses aterosklerosis.

Berdasarkan usia responden yang terbanyak pada kelompok kasus yaitu kelompok usia 41-60 tahun sebanyak 18 responden (52,9\%). Notoatmodjo (2010) menyatakan bahwa usia seseorang erat kaitannya dengan pengetahuan. Semakin cukup usia seseorang, tingkat pengetahuannya akan lebih matang dalam berpikir dan bertindak.

Menurut penelitian Rano, K.S (2017) berdasarkan survei yang dilakukan oleh Joint National Association (JNC) VII, American Heart Associaton, dan Profil kesehatan Jawa Barat risiko menderita hipertensi akan semakin meningkat seiring pertambahan usia.

Hal tersebut dibuktikan dalam penelitian Widjaya, N. Dkk (2018) yang menyebutkan ada hubungan yang signifikan antara usia dengan kejadian hipertensi. Hal ini disebabkan oleh karena tekanan arterial meningkat sesuai dengan bertambahnya usia, terjadinya reugurgitasi aorta, serta adanya proses degenerative, lebih sering pada usia tua.

Berdasarkan tingkat pendidikan responden sebanyak 17 responden $(50,0 \%)$ lebih banyak yang berlatarbelakang pendidikan sekolah dasar (SD). Notoatmodjo (2010) menyatakan pendidikan adalah kegiatan atau proses pembelajaran untuk mengembangkan atau meningkatkan kemampuan tertentu sehingga sasaran pendidikan itu dapat berdiri sendiri. perubahan dan tindakan pemeliharaan dan peningkatan kesehatan yang dihasilkan oleh pendidikan kesehatan didasarkan kepada pengetahuan dan kesadarannya melalui proses pembelajaran. Pengobatan hipertensi bisa disebabkan karena faktor lain selain tingkat pendidikan, dapat pula disebabkan karena perbedaan pekerjaan/kesibukan sehingga penderita hipertensi tidak punya waktu untuk berobat ke puskesmas. Responden yang berpendidikan tinggi maupun yang 
berpendidikan rendah sama-sama ingin sembuh dari peyakitnya sehingga tingkat pendidikan tidak mempengaruhi kepatuhan melakukan pengobatan.

Dalam penelitian Iche, A. L (2017) responden berpendidikan lebih tinggi akan mempunyai pengetahuan yang lebih luas dibandingkan dengan responden yang tingkat pendidikannnya rendah. Berdasarkan hasil analisis bivariat menunjukkan bahwa tidak ada pengaruh yang bermakna antara tingkat pendidikan dengan kepatuhan dalam menjalani pengobatan hipertensi.

Dari data pekerjaan sebanyak 38 responden $(55,9 \%)$ terdapat 17 responden pada kelompok kasus adalah ibu rumah tangga. Hal ini dikarenakan ibu rumah tangga pekerjaannya hanya mengurus rumah setiap hari dan mengurus berbagai macam persoalan didalam rumah tangga, banyak yang dipikirkan sehingga dapat menyebabkan stres dan kurangnya kepedulian terhadap kesehatan dirinya.

Dalam penelitian lain menurut Kanine, E. \& Pobela, N. (2015) hipertensi lebih banyak terjadi pada pekerja seperti swasta/petani dan ibu rumah tangga karena salah satu faktor resikonya adalah berkaitan erat dengan cara hidup kita seperti cara kita menghadapi permasalahan dan dipengaruhi juga oleh berat ringannya pekerjaan seseorang seperti ibu rumah tangga maka kejadian hipertensi paling banyak terjadi pada golongan pekerja seperti mereka.

Tabel 2

Distribusi frekuensi responden berdasarkan tingkat pengetahuan di wilayah kerja Puskesmas Sungai Kakap

\begin{tabular}{lrr}
\hline Pengetahuan & $\mathrm{n}$ & $\%$ \\
\hline Kurang baik & 16 & 23.5 \\
Baik & 52 & 76.5 \\
\hline \multicolumn{1}{c}{ Total } & 68 & 100.0 \\
\hline
\end{tabular}

Sumber:data primer 2019

Hasil penelitian pada tingkat pengetahuan sebanyak 52 responden $(76,5 \%)$ berada dalam kategori baik. Pada kelompok kasus, hampir semua penderita hipertensi $(97,1 \%)$ memiliki tingkat pengetahuan yang baik sedangkan pada kelompok kontrol yang diisi oleh masyarakat yang belum menderita hipertensi hanya 55,9\% memiliki tingkat pengetahuan baik. Pengetahuan atau kognitif merupakan domain yang sangat penting dalam membentuk tindakan seseorang (overt behavior). Demikian pula pernyataan oleh (Notoatmodjo 2014) Pengetahuan adalah hasil tahu seseorang terhadap objek melalui indera yang dimilikinya. Pengetahuan tiap orang akan berbeda-beda tergantung dari bagaimana pengindraannya masing-masing terhadap objek atau sesuatu. Pengetahuan masyarakat dipengaruhi oleh isyarat untuk bertindak. Isyarat untuk bertindak ini dapat berasal dari informasi dari media massa, nasihat dari orang-orang sekitar, pengalaman pribadi atau keluarga.

Hasil temuan dari penelitian bahwa terjadinya hipertensi salah satunya faktor pengetahuan penderita hipertensi yang baik karena penderita yang melakukan kunjungan ke puskesmas cenderung mendapat informasi yang cukup dalam menambah pengetahuannya. Sehingga dapat dinyatakan bahwa sebagian besar responden memiliki pengetahuan yang baik tentang hipertensi. Hal ini dikarenakan puskesmas sering melakukan penyuluhan tentang hipertensi dan melaksanakan program khusus penderita hipertensi untuk masyarakat Sungai Kakap. Selain itu juga, beberapa responden mengatakan bahwa mereka mendengar informasi tentang hipertensi dari media masa dan media elektronik. Pengetahuan yang baik tentang hipertensi dapat mempengaruhi perilaku masyarakat dalam mencegah hipertensi. Secara umum melalui data diatas dapat dimaknai bahwa mayoritas masyarakat akan lebih memiliki motivasi untuk menambah pengetahuan dan mencari informasi mengenai penyakit setelah mereka menderita penyakit itu sendiri. 
Tabel 3

Distribusi frekuensi responden berdasarkan pemanfaatan fasilitas kesehatan di wilayah kerja Puskesmas Sungai Kakap

\begin{tabular}{lrr}
\hline Pemanfaatan & $\mathrm{n}$ & $\%$ \\
\hline Kurang memanfaatkan & 34 & 50.0 \\
Memanfaatkan & 34 & 50.0 \\
\hline Total & 68 & 100.0 \\
\hline Sumber:data primer 2019 & &
\end{tabular}

Hasil penelitian menunjukkan bahwa pemanfaatan fasilitas kesehatan oleh 68 responden pada kelompok kasus yaitu 24 responden $(70,6 \%)$ penderita hipertensi yang memanfaatkan dan sebaliknya bukan penderita sebanyak 24 responden kurang memanfaatkan fasilitas kesehatan. Menurut Notoatmodjo (2011) faktor eksternal yang mempengaruhi perilaku seseorang antara lain; nilai-nilai, adat istiadat, kepercayaan, kebiasaan masyarakat, tradisi, dan sebagainya.

Hanya sebagian kecil penderita hipertensi yang tidak memanfaatkan fasilitas kesehatan karena masyarakat yang telah menderita hipertensi pada umumnya sudah dapat memperoleh pengetahuan tentang kesehatan lewat penyuluhan dan media informasi lainnya serta telah memiliki motivasi dalam memanfaatan fasilitas pelayanan kesehatan sehingga mereka percaya bahwa dengan memanfaatkan fasilitas kesehatan dapat meningkatkan derajat kesehatannya.

Dalam penelitian Ryman, M. N. Dkk. (2016) menurut Twoddle, apa yang dirasakan sehat bagi seseorang bisa saja tidak dirasakan sehat bagi orang lain, karena adanya perbedaan persepsi. Selain itu, ada perbedaan konsep dan persepsi sehat-sakit didalam masyarakat. Dimana mereka merasa dirinya sakit ketika tubuh mereka tidak dapat lagi menjalankan aktivitas, barulah mereka memanfaatkan fasilitas pelayanan kesehatan.

Hasil temuan dari penelitian bahwa pemanfaatan fasilitas kesehatan oleh penderita hipertensi hanya ketika sedang sakit mayoritas responden telah mengetahui tanda dan gejala penyakit hipertensi serta berobat dengan memanfaatkan jaminan kesehatan.

\section{Hasil Analisa Bivariat dan Pembahasan}

Tabel 4

Hubungan tingkat pengetahuan tentang pengendalian hipertensi dengan terjadinya hipertensi di wilayah kerja Puskesmas Sungai Kakap

\begin{tabular}{|c|c|c|c|}
\hline Pengetahuan & $\begin{array}{l}\text { Kasus } \\
\mathrm{n}\end{array}$ & $\begin{array}{c}\text { Kontrol } \\
\mathrm{n}\end{array}$ & $\mathrm{p}$ Value \\
\hline Kurang baik & 1 & 15 & \\
\hline Baik & 33 & 19 & 0,000 \\
\hline Total & 34 & 34 & \\
\hline
\end{tabular}

Sumber:data primer 2019

Dengan melihat tabel 3.4 diatas, diketahui bahwa kelompok kasus lebih banyak dengan kategori baik sebanyak 33 respoden $(97,1 \%)$ dibandingkan kelompok kontrol sebanyak 19 responden $(55,9 \%)$. Dari hasil analisis dengan uji Chi Square diperoleh nilai $\mathrm{p}$ value 0,000 Karena nilai signifikansi pada $0,000<0,05$. maka berdasarkan dasar pengambilan keputusan diatas, dapat disimpulkan bahwa $\mathrm{H} 0$ ditolak dan $\mathrm{Ha}$ diterima. Dengan demikian dapat diartikan bahwa" Ada hubungan yang signifikan antara tingkat pengetahuan tentang pengendalian hipertensi dengan terjadinya hipertensi di wilayah kerja Puskesmas Sungai Kakap". Tterjadinya hipertensi di wilayah kerja Puskesmas Sungai Kakap". Tingkat pengetahuan yang baik pada penderita hipertensi dalam penelitian ini diperoleh pada saat telah menderita hipertensi. Hal ini dapat dimaknai bahwa menderita suatu penyakit tertentu seperti hipertensi dapat secara signifikan mempengaruhi motivasi penderita untuk mencari informasi terkait dan menambah pengetahuannya. Motivasi belajar pada diri penderita sehingga berkeinginan yang mengaktifkan, menggerakkan, menyalurkan dan mengarahkan sikap dan perilaku individu untuk belajar.

Menurut riswandi (2016) salah satu upaya seseorang mendapat pengetahuan yaitu dengan bertanya kepada orang yang memiliki otoritas atau dianggap lebih tahu. Selain itu pengalaman masa lalu dapat menyelesaikan masalah yang dihadapi saat ini. Hasil penelitian ini berkaitan dengan manfaat yang dirasakan atau perceived benefit yang akan dirasakan jika mengadopsi perilaku yang dianjurkan. Perceived benefit merupakan 
persepsi seseorang tentang nilai atau kegunaan dari suatu perilaku baru dalam mengurangi risiko terkena penyakit. Penderita hipertensi yang telah mengetahui bahwa dirinya mengalami hipertensi akan mengetahui tentang kesehatannya.

Wawan dan Dewi (2011) menyatakan pengetahuan merupakan tingkah laku yang sangat penting guna terbentuknya tindakan seseorang (open behavior). Dalam fenomena yang diperoleh dari hasil penelitian ini tindakan yang dimaksud adalah upaya untuk mendapatkan pengobatan dan kesembuhan bukan untuk mencegah penyakit itu datang. Hal ini sejalan dengan penelitian yang dilakukan Wulansari, J. (2013) membuktikan terdapat hubungan Pengetahuan Tentang Hipertensi dengan Pengendalian Tekanan Darah Pada Pasien Hipertensi di Poliklinik Penyakit Dalam RSUD DR. MOEWARDI Surakarta.

Hasil temuan dilapangan bahwa dengan didapatkan pengetahuan penderita hipertensi yang melakukan kunjungan ke puskesmas dapat menjadi acuan dalam upaya meningkatkan pengetahuan penderita yang tidak melakukan kunjungan ke puskesmas sehingga penderita hipertensi akan melakukan tindakan sesuai dengan harapan perawat.

Hasil analisis OR mempunyai nilai 0,038 yang mempunyai arti responden dengan tingkat pengetahuan yang kurang baik memiliki risiko 0,038 kali terkena hipertensi. OR kurang dari 1, maka tingkat pengetahuan dengan terjadinya hipertensi berkorelasi negatif, dan kehadiran pengetahuan mengurangi peluang terjadinya hipertensi.

Tabel 5

Hubungan tingkat pemanfaatan fasilitas kesehatan dengan terjadinya hipertensi di wilayah kerja Puskesmas Sungai Kakap

\begin{tabular}{|c|c|c|c|}
\hline Pemanfaatan & $\begin{array}{c}\text { Kasus } \\
n\end{array}$ & Kontrol & p Value \\
\hline Kurang & 10 & 24 & \\
\hline memanfaatkan & & & 0,002 \\
\hline Memanfaatkan & 24 & 10 & \\
\hline Total & 34 & 34 & \\
\hline
\end{tabular}

Sumber: data primer 2019
Dengan melihat tabel 5.5 diatas, diketahui bahwa kelompok kasus lebih banyak memanfaatkan fasilitas kesehatan sebanyak 24 responden (70.6\%). Berbanding terbalik pada kelompok kontrol yang lebih banyak kurang memanfaatkan fasilitas kesehatan sebanyak 24 responden (70.6\%). Dari hasil analisis dengan Chi Square diperoleh nilai $\mathrm{p}$ value 0,002 . Karena nilai signifikansi $0,002<0,05$, maka berdasarkan dasar pengambilan keputusan diatas, dapat disimpulan bahwa $\mathrm{H} 0$ ditolak dan $\mathrm{Ha}$ diterima. Dengan demikian dapat diartikan bahwa" Ada hubungan yang signifikan antara tingkat pemanfaatan fasilitas kesehatan dengan terjadinya hipertensi di wilayah kerja Puskesmas Sungai Kakap".

Hal ini menunjukkan bahwa penderita hipertensi dengan persepsi sehat-sakit yang sebenarnya dapat merasakan risiko pribadi atau kerentanan yang merupakan salah satu persepsi yang lebih kuat dalam mendorong orang untuk mengadopsi perilaku sehat. Semakin besar risiko yang dirasakan, semakin besar kemungkinan terlibat dalam perilaku untuk mengurangi risiko tersebut dengan mencari tahu kemudian memahaminya. Masyarakat memanfaatkan fasilitas pelayanan kesehatan yang dipercaya mampu mengatasi masalah kesehatan yang mereka alami. Keinginan ini muncul akibat dari penderita hipertensi yang bergerak untuk mencapai tujuan dalam meningkatkan derajat kesehatannya. Hal ini bertolak belakang dengan pepatah yang menyebutkan lebih baik mencegah daripada mengobati.

Menurut masyarakat, sakit merupakan hal yang bisa dirasakan oleh seseorang dimana jika mereka merasa dirinya sakit maka mereka akan merasa butuh untuk pergi ke fasilitas pelayanan kesehatan. Responden juga mengatakan bahwa sakit itu ketika tubuh tidak dapat lagi menjalankan aktivitas. Ketika responden tidak dapat lagi menjalankan aktivitas, barulah mereka merasa butuh untuk memanfaatkan fasilitas pelayanan kesehatan. Sebagian responden jika mereka merasa tubuhnya sakit dan belum terlalu parah mereka cenderung melakukan pengobatan sendiri dengan membeli obat diwarung atau 
dibiarkan saja sampai penyakit itu sembuh dengan sendirinya.

Arifin (2016) menyatakan persepsi positif tentang penyakit yaitu seseorang dapat memahami penyakit dan cara untuk mengontrol penyakitnya dengan baik, akan tetapi sebaliknya apabila persepsi negatif tentang penyakit yaitu seseorang tidak dapat dengan baik memahami penyakit dengan cara yang tepat untuk mengontrol penyakitnya.

Dalam penelitian Kanine, E. \& Pobela, N. (2015) menyebutkan beberapa faktor yang signifikan menyebabkan motivasi penderita hipertensi dalam pemanfaatan fasilitas kesehatan yaitu faktor kunjungan, jarak ke puskesmas, kepemilikan asuransi dan sosial ekonomi. Hal ini yang menyebabkan penderita tidak melakukan kontrol kesehatan rutin. Oleh karena itu, diperlukan sikap petugas kesehatan dalam hal penyuluhan kesehatan yang dilakukan dengan cara menyebarkan pesan, menanamkan keyakinan, sehingga masyarakat tidak hanya sadar, tahu, dan mengerti, tetapi juga mau dan bisa melakukan suatu anjuran yang ada hubungannya dengan kesehatan.

Hasil analisis OR mempunyai nilai 5,760 yang mempunyai arti responden yang kurang memanfaatkan memiliki risiko 5,760 kali lebih besar terkena hipertensi. OR lebih dari 1, maka kurang memanfaatkan fasilitas kesehatan dan terjadinya hipertensi (berkorelasi) dalam arti bahwa, kurangnya responden dalam memanfaatkan fasilitas kesehatan dapat meningkatkan peluang terjadinya hipertensi.

\section{KESIMPULAN}

1. Karakteristik responden di wilayah kerja Puskesmas Sungai Kakap dalam penelitian ini sebagian besar responden berjenis kelamin perempuan sebanyak 42 responden dengan 20 responden $(58,8 \%)$ pada kelompok kasus. Usia responden kategori umur 41-60 tahun sebanyak 33 responden dengan kelompok kasus 18 responden (52,9\%). Sebagian besar pendidikan terakhir yaitu Sekolah Dasar (SD) sebanyak 32 responden diantaranya terdapat 17 Responden (50,0\%) pada kelompok kasus. Mayoritas pekerjaan responden sebagai ibu rumah tangga, sebanyak 38 responden dengan kelompok kasus sebanyak 17 responden $(50,0 \%)$.

2. Tingkat pengetahuan dalam kategori baik sebanyak 52 responden $(76,5 \%)$. Karena penderita hipertensi yang melakukan kunjungan ke puskesmas cenderung mendapat informasi yang cukup dalam menambah pengetahuannya.

3. Tingkat pemanfaatan fasilitas kesehatan oleh responden yang memanfaatkan dan yang kurang memanfaatkan sama banyak yaitu masing-masing 34 responden (50.0\%). Akan tetapi, 24 responden penderita hipertensi lebih banyak memanfaatkan fasilitas kesehatan untuk meningkatkan derajat kesehatannya.

4. Terdapat hubungan pada tingkat pengetahuan tentang pengendalian hipertensi dengan terjadinya hipertensi kelompok kasus dan kontrol di wilayah kerja Puskesmas Sungai Kakap, dengan $\mathrm{p}$ value $=0,000$ yang berarti $\mathrm{H} 0$ ditolak dan Ha diterima.

5. Terdapat hubungan tingkat pemanfaatan fasilitas kesehatan dengan terjadinya hipertensi kelompok kasus dan kontrol di wilayah kerja Puskesmas Sungai Kakap dengan $\mathrm{p}$ value $=0,002$ yang berarti $\mathrm{H} 0$ ditolak dan Ha diterima.

\section{DAFTAR PUSTAKA}

Arifin, F. F. (2016). Hubungan Antara Persepsi Tentang Penyakit Dengan Kepatuhan Minum Obat Hipoglikemik Oral (Oho) di Puskesmas Srondol Kota Semarang. Semarang: Skripsi Prodi Ilmu Keperawatan UNDIP.

Data Dinas Kabupaten Kubu Raya. 2018

Data Puskesmas Sungai Kakap. 2019

Dinas Kesehatan. (2018). Profil Kesehatan Kabupaten Kubu Raya 2018.

Hesriantica, D.Z \& Diana, R.R. (2017). Hubungan Pengetahuan dan Riwayat Hipertensi Dengan Tindakan Pengendalian Tekanan Darah Pada 
Lansia. Jurnal Berkala Eoidemologi, volume 5 Nomor 2, Mei 2017, hlm.174-184.

Iche, A. L (2017). Determinan Kepatuhan Berobat Pasien Hipertensi Pada Fasilitas Kesehatan Tingkat I. Universitas Sriwijaya: Jurnal Penelitian dan Pengembangan Pelayanan Kesehatan, Vol. 1, Agustus 2017: 58-65.

Kanine, E. \& Pobela, N. (2015). Motivasi Penderita Hipertensi Di Desa Kobo Kecil Memanfaatkan Pelayanan Kesehatan Di Puskesmas Kotabangun.

Kementerian Kesehatan Republik Indonesia, (2018). Hasil Utama Riskesdas 2018. Badan Penelitian dan Pengembangan Kesehatan.

Kementerian Kesehatan Republik Indonesia, (2018). Profil kesehatan Indonesia 2017: health statistik. Jakarta: Katalog dalam terbitan kementrian kesehatan RI.

Kementerian Kesehatan Republik Indonesia, (2018). Untuk Indonesia yang Lebih Sehat. Www.depkes.go.id. Di peroleh 18 Maret 2019.

Notoatmodjo, S. (2010). Metodologi Penelitian Kesehatan. Jakarta: Rineka Cipta.

Notoatmodjo, S. (2010). Promosi Kesehatan Teori dan Aplikasinya. Jakarta: Rineka Cipta.

Notoatmodjo, S. (2014). Promosi Kesehatan Teori dan Aplikasinya. Edisi revisi. Jakarta: Rineka Cipta.

Novitaningtyas, T. (2014). Hubungan Karakteristik (Umur, Jenis Kelamin, Tingkat Pndidikan) dan Aktivitas Fisik dengan Tekanan Darah Pada Lansia di Kelurahan Makamhaji kecamatan Kartasura Kabupaten Sukoharjo. Naskah Publikasi diakses 22 Juli 2019.

Pemerintah Kalimantan Barat Dinas Kesehatan. (2017). Profil Kesehatan Kalimantan Barat tahun 2017.
Putri, Q. R. dkk. (2015). Faktor-Faktor yang Berhubungan dengan Kepatuhan Pengobatan pada Penderita Hipertensi Diwilayah Kerja Puskesmas Kedungmundu Kota Semarang: UJPH 4 (3) (2015)

Rano, K. Dkk (2017). Pengukuran Tingkat Pengetahuan Tentang Hipertensi Pada Pasien Hipertensi Di Kota Bandung: Sebuah Studi pendahuluan. Jurnal Farmasi Klinik Indonesia, Desember 2017. Vol. 6 No. 4, hkm 290-297.

Riswandi. (2016). Hubungan Pengetahuan dan Sikap Ibu Terhadap Penyakit DBD di Sidomulyo Pekanbaru. Pekanbaru.

Ryman, M. N. Dkk. (2016). Faktor-Faktor yang Berhubungan dengan Pemanfaatan Pelayanan Kesehatan di Wilayah Kerja Puskesmas Tambarana Kecamatan Poso Pesisir Utara Kabupaten Poso. Jurnal Pengembangan Kota (JPK). Volume 4 No. 1 (29-39).

Ulya, Z. dkk. (2017). Pengaruh Pendidikan Kesehatan dengan Media Poster Terhadap Pengetahuan Manajemen Hipertensi pada Penderita Hipertensi: Jurnal Keperawatan Soedirman (The Soedirman Journal of Nursing), Volume 12, No.1 Maret 2017

Wawan, A. \& Dewi M. (2010). Teori \& Pengukuran Pengetahuan, Sikap, dan Perilaku Mannusia. Yoyakarta: Nuha Medika.

Wulansari, J. Dkk. (2013). Hubungan Pengetahuan Tentang Hipertensi dengan Pengendalian Tekanan darah Pada Pasien Hipertensi di Poliklinik Penyakit Dalam di RSUD DR. Moewardi Surakarta. Biomedika, volume 5 nomor 1, febuari 2013. 